\title{
Antropometria Aplicada ao Design de Produtos: Um Estudo de Caso de Dimensionamento de Tesouras de Corte e Costura
}

\author{
Anthropometry apllied to product design: a case study of scissors for cutting and \\ sewing
}

MARIÑO, Suzi; D.Sc; Universidade do Estado da Bahia e Universidade Federal da Bahia

suzimarino@gmail.com

SILVEIRA, Carina; D.Sc Universidade do Estado da Bahia e Universidade Federal da Bahia

carinassilveira@gmail.com

SANTOS, Ruth; Universidade do Estado da Bahia

ruth.designmoda@gmail.com

SILVA Paulo; Universidade do Estado da Bahia

henriqueoupaulo@gmail.com

\section{Resumo}

Este artigo traz uma discussão sobre a importância da aplicação da antropometria e a seleção do percentil correto para o dimensionamento de produtos, tendo como estudo de caso a tesoura de corte e costura. Foi necessária uma investigação e coleta de informações a respeito do caso estudado, tornando-o mais compreensível para discutir sobre a biomecânica da mão, pegas e manejos. A tesoura de corte e costura, já que é um produto muito utilizado, tanto de forma doméstica como profissionalmente, exige esforços repetitivos para profissionais que trabalham na área de confecção, podendo causar lesões e doenças osteomusculares tendíneas. Dessa forma, vimos a necessidade de dedicar o estudo que comprove a importância do desenvolvimento de uma tesoura de corte e costura para atender aos requisitos da tarefa e diminuir ou até eliminar os riscos de lesões. Ressaltamos que as recomendações elaboradas apenas servem como referência para um primeiro passo ao se dimensionar uma tesoura de corte e costura.

Palavras Chave: antropometria; tesoura; percentil e dimensão.

\begin{abstract}
This article addresses the importance of both the application of anthropometry and selection of the correct percentile for product sizing, offering cutting and sewing scissors as a study case. It was necessary to investigate and collect information about the studied case, making it more understandable for further discussion of the biomechanics of the hand, and handles. The cutting and sewing scissors, widely used products in both domestic and professional settings, require repetitive efforts from professionals working in the clothing sector, which may lead to injuries and tendinous musculoskeletal diseases. Thus, we identified the necessity to dedicate the study that proves the importance of developing a shear cut and sewing to meet the requirements of the task and reduce or even eliminate the risk of injury. It is noteworthy that the recommendations made serve only as a reference for a first step when scissors are cut and sewn.
\end{abstract}

Keywords: anthropometry; scissors; percentile and dimension. 


\title{
1 Introdução
}

As medidas do corpo humano têm despertado interesse desde a existência da humanidade. Em vários períodos da nossa história, pode-se constatar estudiosos que utilizaram as medidas do corpo humano como referência para suas obras, como a antiga Grécia que as utilizou para construção das mais perfeitas obras que a humanidade já teve conhecimento.

O termo antropometria deriva do grego antropos, significando "humano", e metrikos, que significa "medida de". Segundo Moraes (1983), a estandardização das medidas do crânio foi resultado do Congresso Internacional de Antropólogos, realizado em Mônaco, em 1906, pois, até então, cada investigador usava técnicas de medição e nomenclaturas diferentes. Como consequência disso, as comparações entre os resultados eram difíceis.

\begin{abstract}
As 38 medidas do crânio e 19 da cabeça e face do vivente tornaram-se padrões seguidos por antropólogos de todo o mundo. Uma segunda estandardização das medidas do vivente, excluindo-se a cabeça, aplicava-se principalmente ao esqueleto, e foi resultado do 'Congresso Internacional de 1912', em Genebra. Em 1913, Martin publicou a primeira edição de seu famoso "Lehrbuch der Anthropologie", que permaneceu como obra básica por várias décadas e que, de fato, unificou largamente as técnicas de medida. (MORAES, 1983).
\end{abstract}

Para Boueri (1991), a antropometria é a aplicação dos métodos científicos de medidas físicas nos seres humanos, buscando determinar as diferenças entre indivíduos e grupos sociais, com a finalidade de se obter informações utilizadas nos projetos de arquitetura, urbanismo, design e de engenharia, e, de um modo geral, para melhor adequar esses produtos a seus usuários.

Como se sabe, todas as populações são compostas de indivíduos de diferentes tipos físicos que apresentam diferenças nas proporções de cada segmento do corpo. Com as viagens de Marco Polo (1273-1295), segundo Guimarães (2004), foi revelada a existência de um grande número de raças que diferiam, inclusive, em termos de dimensões do corpo.

A preocupação com a antropometria teve impulso a partir da década de 40 do século $X X$, pelas exigências da produção em massa, quando superdimensionamentos de poucos centímetros passaram a significar aumento considerável nos custos de produção de centenas de milhares de um mesmo produto. Não se pode deixar de mencionar que em um projeto aeroespacial cada centímetro ou quilograma pode comprometer o desempenho da nave, e um controle fora do raio de ação de um operador de um sistema complexo pode representar a resposta tardia com resultados catastróficos.

Até a década de 1950, havia uma preocupação em estabelecer padrões nacionais antropométricos. Mas, a partir de então, a economia começou a se internacionalizar com a expansão da produção em massa, culminando na globalização atual da economia. Hoje, é possível atender os padrões de qualquer mercado, já que é possível acessar tabelas de muitas populações que habitam este planeta. Algumas estão tabuladas em mídia eletrônica, outras em papel, mas o que importa é a confiabilidade dos dados de uma determinada população. (GUIMARÃES, 2004).

Com o passar dos anos, a necessidade por medidas mais exatas do ser humano foi crescendo. Hoje, estas medidas são imprescindíveis para o dimensionamento de produtos eficientes. Em todo o mundo vem crescendo a Antropometria aplicada ao dimensionamento de produtos. 
Segundo Moraes (1983), os objetivos e atitudes dos primeiros pesquisadores eram um tanto diversos daqueles dos antropometristas ligados à Ergonomia. Consequentemente, seus métodos eram diferentes.

No entanto, muitos de seus resultados ainda são úteis ao designer, e seus métodos podem ser adaptados aos problemas presentes. Algumas de suas descobertas são ainda os únicos dados disponíveis; assim, o conhecimento de seus métodos é vital para o entendimento de alguns dados. Muitos trabalhos aplicados usam técnicas que vieram dos antropólogos físicos, mas ocorreram muitas mudanças no enfoque, no tipo de dados coletados, nos instrumentos especiais para medição que surgiram de necessidades práticas. Em particular, a necessidade de estabelecer relações espaciais em coordenadas tri-dimensionais, envolvendo profundidades e alcances, desenvolveu-se como característica da aplicação da Antropometria ligada à Ergonomia. O designer deve conhecer não só o comprimento e a largura das partes do corpo, mas também onde elas se localizam quando da atividade humana. Tal fato determinou, não só a necessidade de outros métodos que não os de medição com os antropômetros tradicionais, como também a proposição de novas variáveis como largura bi-deltóide, largura cotovelo a cotovelo em abdução, profundidade nádegajoelho etc. (MORAES, 1983)

\subsection{A Antropometria Aplicada ao Design de Produtos}

Moraes (1983) definia os objetivos da antropometria como:

- Obter dados sobre as medidas do corpo que descrevam com confiabilidade as características, capacidades de alcance, superfície de trabalho para uso normal e máximo, ângulos de conforto, distribuição de peso, volume etc., para grupos, raças ou descendência estudada;

- Publicar os dados de forma que possam ser usados com facilidade e segurança para comparações e deduções ergonômicas;

Para o dimensionamento de produtos ergonômicos faz-se necessária a aplicação correta das dimensões humanas. Hoje a evolução das formas de análise de dados estatísticos aperfeiçoa as informações levantadas em uma pesquisa de dados antropométricos. Moraes (1983) também ressaltava que:

[...] mais importante, ainda, foi a inovação de métodos computadorizados para a manipulação de modelos matemáticos dos processos biomecânicos. Os conceitos e amplitude dos dados disponíveis atualmente colocaram uma grande variedade de modelos matemáticos do ser humano dentro do âmbito da exequibilidade, e pesquisadores já começaram a desenvolver tais modelos. Com estes objetivos identificaram áreas específicas de conhecimento que são fracos e deficientes em dados diretamente úteis ao desenvolvimento de tais modelos conceituais. Há um interesse crescente e uma nova ênfase nas descrições tridimensionais do corpo e na pesquisa de medições de articulações funcionais do corpo. (MORAES, 1983).

A autora lembra que um bom início é tentar estandardizar a nomenclatura das variáveis antropométricas, denominando e localizando corretamente os pontos a serem medidos.

\subsection{Fatores que Influenciam as Diferenças Antropométricas}

De acordo com Moraes (1983), os fatores que influenciam as diferenças antropométricas podem ser divididos em fatores intrínsecos e extrínsecos. Boueri (1991) define estes dois tipos; observando que os intrínsecos são fatores próprios da pessoa, tais como alinhamento postural e mobilidade das juntas, e dá como exemplo a gravidez, que altera a linha do corpo ou, ainda, o fato 
de que, do nascimento até os 25 anos de idade, aumentamos de estatura $70 \%$ e, depois, decrescemos até $7,5 \mathrm{~cm}$. Os fatores extrínsecos são conceituados por ele como fatores externos, como clima e vestuário, e cita como exemplo o fato de que a roupa altera as dimensões do corpo e as suas condições dinâmicas.

Quaresma (2001) subdivide os fatores intrínsecos em sexo, idade, etnia e raça, tipo de atividade, nível socioeconômico e a tendência secular ou gerações da população e divide os fatores extrínsecos em vestuário e equipamentos, postura e horário. A autora enfatiza que, para a correta seleção da população usuária, devem ser levados em consideração todos estes fatores.

\subsection{Aplicação dos Dados Antropométricos ao Dimensionamento da Zona Interfacial}

\subsubsection{Definição de Percentis Corretos}

De acordo com Soares e Siqueira (2002), percentis são usados para entender bem uma distribuição. Para isso, é necessário que se conheçam valores acima ou abaixo dos quais se encontra uma determinada porcentagem dos dados. Boueri (1991) define percentil como uma medida de dispersão das dimensões do corpo humano para a distribuição estatística, sendo a única maneira de determinar o padrão dimensional, sem incorrer em erro de conceitos matemáticos nas aferições de medidas.

A utilização de percentis é uma forma de dividir uma distribuição normal desde o valor mínimo até o máximo, seguindo uma sequência ordenada. Os percentis extremos, sejam máximos ou mínimos, apresentam pequena probabilidade de incidência.

Guimarães (2004) explica mais detalhadamente o conceito de percentil da seguinte forma: o $x^{0}$ percentil significa que $x \%$ das pessoas do levantamento antropométrico considerado tem medidas inferiores ou iguais às deste percentil, e que $100-x \%$ das pessoas tem medidas superiores às deste percentil. Por exemplo, o valor do 950 percentil para estatura demonstra que $95 \%$ da população têm uma medida de estatura menor ou igual ao do 950 percentil e que $5 \%$ possuem estatura com valor maior. Uma medida do 5 o percentil mostra que $5 \%$ da população possui esta medida com valor menor ou igual a deste percentil e que $95 \%$ possuem esta medida com valor maior. 050 o percentil corresponde à média.

Moraes (1983) esclarece que, devido às significantes variações nos tamanhos do corpo de cada indivíduo, as 'médias' são de pouca utilidade. Portanto é necessário trabalhar com limites de variação. Estatisticamente, pode-se constatar que as medidas do corpo humano, de qualquer população dada, distribuem-se de tal modo que, de alguma maneira, cairão em algum lugar pelo meio da curva de distribuição, enquanto um pequeno número de medidas extremas cairá em uma das extremidades do espectro. Por isso, a maioria dos dados antropométricos é, em geral, apresentada sob a forma de percentis. A população é dividida, objetivando seu estudo, em 100 percentis, a partir do menor para o maior, em relação a algum tipo específico de dimensão corporal. Embora o limite máximo de faixa de usuários de um produto compreenda todo o espectro, ou seja, $100 \%$ da população, para esta faixa o projeto é, em geral, técnica e economicamente inviável.

A autora conclui que, num projeto, objetiva-se, em princípio, sua adaptação às características dimensionais de, no mínimo, $90 \%$ dos usuários, ou seja, as pessoas cujas dimensões variam entre os 50 ao $95 \%$ percentis. Porém, quando se trata de ferramentas e produtos que exigem mais precisão de preferência, o uso do 2,5 o ao 97,5 o é mais recomendado, como é o caso deste estudo de dimensionamento de tesouras de corte e costura, pois assim atende-se à $95 \%$ da 
população usuária.

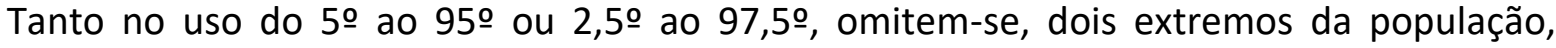
excetuando-se naturalmente, os casos dos equipamentos como já mencionado, que devem considerar necessariamente os indivíduos extremos; assim como, uma saída de emergência, por exemplo. Existem, também, produtos que são fabricados com dimensões diversas, de modo que cada combinação de dimensões atenda a uma faixa da população, como os números de calçados, os manequins de peças do vestuário etc. (MORAES, 1983).

\section{Atividade de Corte e Costura}

. Comprar o tecido, escolher a modelagem e dar asas à imaginação: a arte de costurar ainda conquista muitos adeptos até hoje, seja por necessidade, diversão ou trabalho. Assim tem sido a atividade de costurar, seja por lazer ou profissionalmente, para indústria ou como autônoma. E quanto tempo tem esta profissão? Os dados são imprecisos, mas relatos afirmam que as agulhas mais antigas, feitas de osso e marfim, foram fabricadas há mais de 30 mil anos. Esta arte manual acompanha a história dos hábitos humanos, já que, de acordo com a tecnologia disponível em cada época da história, os trajes ganham novos recursos e sofisticação. Dizem os historiadores que, segundo Joffily (2014), no passado, quem costurava eram os homens, que chefiavam os ateliers de costura e como tais eram chamados Tailleurs de Ville. Esses profissionais masculinos, altamente qualificados, surgiram na França com o desenvolvimento urbano, na Idade Média, mais precisamente nos séculos XII e XIII. E a corporação dos Tailleurs de Ville era um "clube do bolinha". Lá, mulher não entrava. A mesma autora relata que:

Foi apenas no século XVII que as mulheres se reuniram e resolveram lutar contra a discriminação: queriam ter direito a criar roupas femininas. Já prevendo uma contestação por parte dos homens, que detinham o poder sobre o mercado de roupas feitas sob medida, o texto escrito pelas mulheres pedia a liberação do trabalho feminino em nome da castidade e da modéstia, duas fortes razões para que as mulheres fossem vestidas por outras mulheres e não por homens. o rei Luis XIV aceitou a petição e a partir do ano de 1675 elas foram autorizadas a trabalhar como costureiras e a ter o seu próprio negócio. (JOFFILY, 2014, p. 1),

O ofício permaneceu como uma arte de especialista, passada de geração em geração para homens e mulheres, até a Revolução Industrial. Nesta fase, como em diversos outros ofícios, a costura ganhou padronização e produção em série, mais rápida e adequada ao crescente mercado consumidor. (MAGAZINE, 2016).

Tais atividades que requer em grande parte do tempo o uso de tesouras, sendo o seu uso classificado como atividade repetitiva que segundo Renault (2014) como relator de processo judicial sobre doenças osteomusculares tendíneas em costureiras, afirma que:

A experiência advinda de outras reclamações envolvendo empregadas que ativaram a sua força de trabalho na indústria de vestuário, permite concluir que a tendinite de ombro e as cervicalgias, de maneira geral, acometem, com grande frequência, as costureiras, em face da postura e dos movimentos repetitivos que são inerentes ao exercício da função. Não são poucos os casos de acometimento de doenças osteomusculares tendíneas, principalmente dos membros superiores, decorrentes de condições inadequadas de ergonomia em que o trabalho é realizado. (Renault, 2014, p.1) 
De acordo com Dul \& Weerdmeester (1995), para costurar, muitas atividades manuais são executadas e estas exigem um acompanhamento visual, isso significa que o tronco e a cabeça ficam inclinados para frente. $\mathrm{O}$ pescoço e as costas ficam submetidos a tensões mantidas por longos períodos, o que poderá acarretar dores. O dorso pode ser submetido também a tensões, quando for necessário girar o corpo, estando o trabalhador em um assento fixo.

Deimling (2014) diz que a indústria de confecções tem se apresentado como uma importante geradora de renda e emprego nas mais diversas regiões do País. Por se tratar de um setor de intensa utilização de mão-de-obra, são constantes as preocupações para com a saúde e segurança dos funcionários destas indústrias. A mesma autora ainda acrescenta que, a pressão ocasionada sobre as empresas em função da alta concorrência, têm proporcionado estudos voltados para redução de custos e aumento de produtividade. Esses fatores de certa forma, cobram uma produtividade maior dos trabalhadores, e como consequência, muitos casos de lesões por operações repetitivas.

Ainda na mesma linha, Sena (2008) cita que no Brasil, de acordo com as estatísticas do Instituto Nacional de Seguridade Social (INSS), os distúrbios osteomusculares relacionados ao trabalho (DORT) são a segunda causa de afastamento dos empregados de suas atividades (LAMPERT, 2005 apud SENA, 2008).

Em pesquisa realizada por Sena (2008), foi constatado que 93,5\% das costureiras trabalham nove horas diárias, com intervalo de uma hora e meia de almoço e uma pausa de quinze minutos, no turno da tarde. No período em que existe uma demanda maior pelo produto fabricado, na maioria das vezes, realiza-se o "turnão", que são horas extras de trabalho. Cerca de 90,3\% das funcionárias excedem seu horário habitual em quatro horas, com um intervalo de, apenas, trinta minutos para o jantar.

Em relação a horas trabalhadas, Kroemer e Grandjean (2005) e lida e Buarque (2016), também afirmam que o trabalho estático por mais de oito horas é altamente fatigante e, quando realizado frequentemente, pode lesar articulações, tendões e ligamentos. Quando não for possível evitar esse tipo de trabalho, recomenda-se que devem ser concedidas pausas de curta duração, mas com elevada frequência, para permitir relaxamento muscular e alívio da fadiga.

Dados como esse ressaltam a intensidade da tarefa e como consequência, a ferramenta de trabalho principal tem sido a tesoura, o que pode-se concluir que grande parte das lesões decorre do uso de tesouras que não atendam às dimensões das mãos desses profissionais.

Jarufe (2009) afirma que, em relação à usabilidade é necessário utilizar tesouras e outros implementos com manejo ergonômico; evitar objetos cortantes na medida do possível; elaborar um redesign dos equipamentos que facilitem a preparação da máquina.

Dessa forma, vimos a necessidade de dedicar estudo que comprove a necessidade do desenvolvimento de uma tesoura de corte e costura para atender aos requisitos da tarefa e diminuir ou até eliminar os riscos de lesões.

Nesta etapa da pesquisa realizamos a análise da tarefa e realizamos o levantamento das dimensões e iniciamos os desenhos com estudo dos movimentos da mão no uso da tesoura para posteriormente gerar as alternativas e os testes de validação ergonômica. 


\section{Análise da Tarefa}

Em toda tarefa de cortar material para costura, deve-se considerar, como fatores de desempenho da atividade, a altura da bancada de apoio, o tipo do tecido, a da cadeira quando é possível executar esta tarefa sentado. Tais fatores devem estar intrinsecamente relacionados, pois, caso contrário, serão exigidas do profissional maior ou menor esforço e postura incorretas, assim como, demasiado esforço na mão e no braço. Estes fatores poderão prolongar ou minimizar o tempo de realização da atividade, bem como influenciarão na qualidade final do trabalho e desempenho do profissional.

\section{Problematização}

Assim, com a análise das tesouras utilizadas por profissionais de corte e costura, foi possível detectar alguns problemas que podem provocar custos humanos aos profissionais deste ramo. Ao se fazer a análise da tarefa, foi observado que muitos profissionais de corte e costura e estudantes aplicam mais força na realização da atividade quando o tecido é mais espesso. Com isso, ocorre um uso excessivo dos tendões para vencer uma resistência acentuada; além de dores, que são ocasionadas pelo esforço, a longo prazo podem surgir lesões.

A tesouras de corte e costura existentes no mercado constitui um outro fator que pode acarretar custos humanos aos seus usuários. A maioria das observadas não apresentam formas orgânicas e anatômicas, que se adequem aos vários formatos de mãos. Observamos que o design destas não minimiza problemas acionais como o esforço, as manobras repetitivas com as mãos, além de não evitar ou amenizar os desvios radial e ulnar (Figura 1), nem a flexão do punho e compressão dos tendões no carpo, que este profissional faz no momento da realização da tarefa. É importante salientar que, segundo Seixas, Silveira e Pequini (2001), esse esforço nos músculos das mãos, as manobras repetitivas e os desvios radial e ulnar podem ocasionar lesões por efeitos traumáticos cumulativos e lesões por esforços repetitivos - LER/DORT.

Figura 1 - Desvios radial e ulnar da mão.
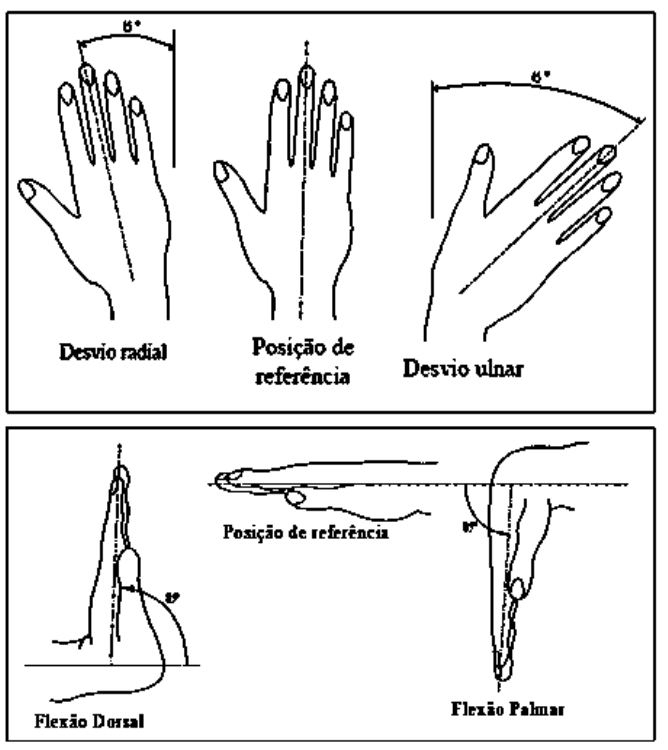

Fonte: Seixas, Silveira e Pequini (2001) 
Pode-se notar também a existência de problemas interfaciais, onde a postura do profissional pode causar danos físicos que são prejudiciais e que resultam em inadequações do campo de visão/tomada de informações do envoltório acional/alcances, e do posicionamento de componentes comunicacionais, ocasionando prejuízo para o sistema musculoesquelético. A postura de trabalho imposta, na maioria do tempo em pé e com movimentação, para a execução da tarefa pode modificar o custo energético do conjunto da atividade, proporcionando ao indivíduo dores musculares, a diminuição do ritmo de trabalho, esgotamento precoce, além de efeitos a longo prazo: sobrecarga imposta ao aparelho respiratório, formação de edemas e varizes e afecções nas articulações, principalmente na coluna vertebral. (Seixas, Silveira e Pequini, 2001). O profissional mantém-se com o tronco e a cabeça inclinados para frente, esta postura errada pode provocar dores e doenças na região lombar, nos músculos eretores da espinha, deterioração dos discos intervertebrais da região lombar e cervical e dores no pescoço.

\section{Estudo dos Movimentos da Mão no Uso da Tesoura}

Após observação dos profissionais desenvolvendo a tarefa cortando tecidos foram realizados estudos dos movimentos das mãos de usuários do percentil 2,50 da mulher ao percentil $97,5^{\circ}$ do homem com as tesouras para verificar as manobras dos desvios radial e ulnar.

Figura 2 - Estudo dos movimentos das mãos dos percentis $2,5^{\circ}$ da mulher e $97,5^{\circ}$ do homem no uso da tesoura.

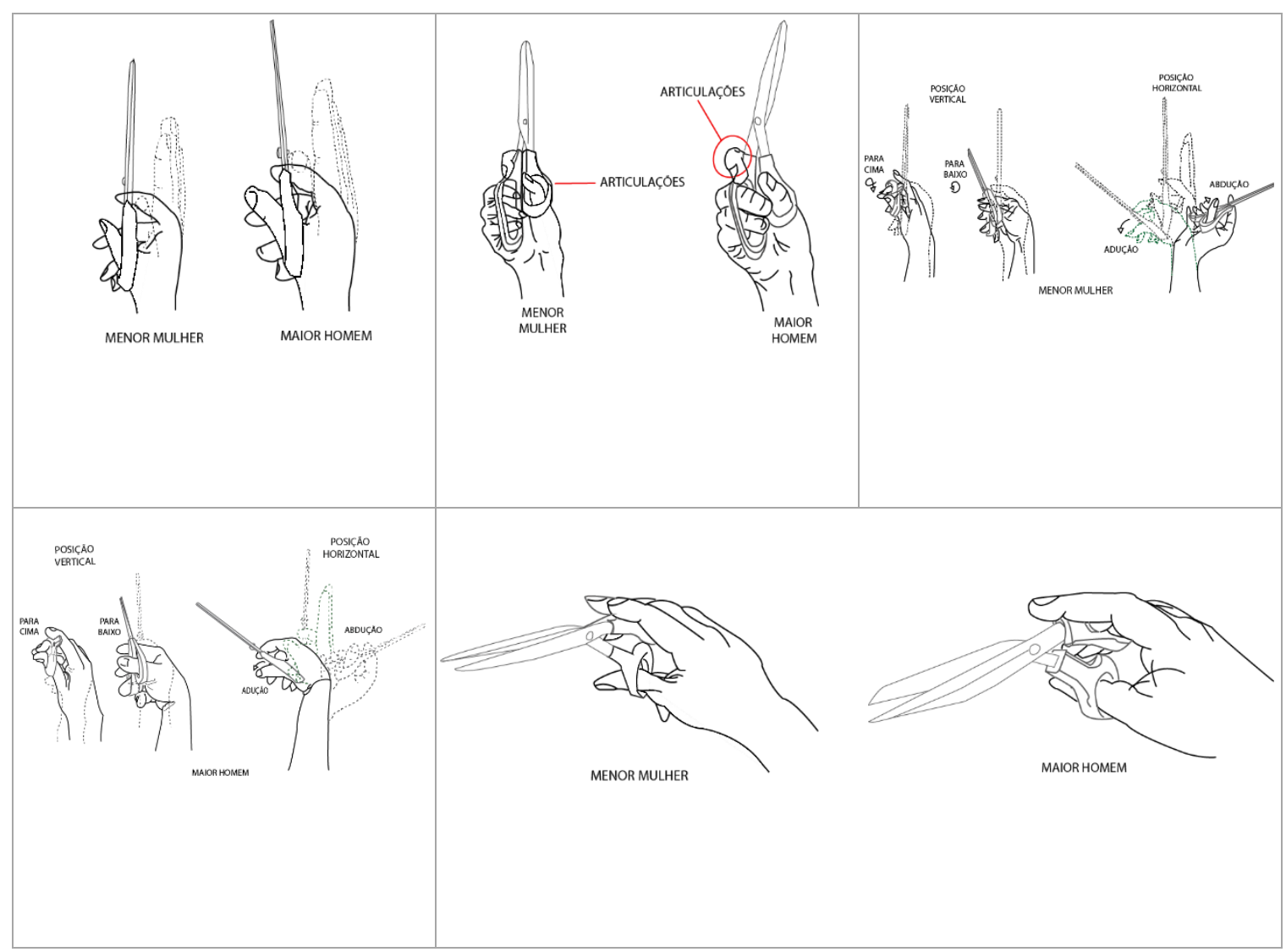

Fonte: Desenho elaborado pelos autores, com base na problematização (2016). 


\section{Levantamento de Dados Antropométricos para o Dimensionamento de Tesoura de Corte e Costura}

\subsection{Seleção de Variáveis Antropométricas}

Além da seleção dos percentis corretos para o desenvolvimento de um projeto de produto, faz-se necessário a correta seleção das variáveis antropométricas. Na verdade, uma das maiores razões de erro na aplicação de dados antropométricos encontra-se na seleção incorreta da variável pertinente.

É frequente a utilização da estatura para definir o local de melhor visualização de mostradores, quando o certo seria utilizar a altura do nível dos olhos e, a partir daí, delimitar o campo de visão. Outro erro cometido é a seleção da largura de ombros bideltóide, quando o que se quer é dimensionar a largura do apoio lombar. Neste caso, seria melhor, então, a largura do tórax entre as axilas, para não atrapalhar a movimentação do usuário. Tal fato explica parcialmente por que, até em países onde existe profusão de levantamentos, os produtos não são bem dimensionados (MORAES, 1994, p.37).

Moraes (1983, p.327) lembra que se deve observar a especificidade do projeto, explicitada a partir da análise da tarefa, pois só dessa forma é que se determinará, em última instância, as variáveis que serão necessárias ao dimensionamento da estação de trabalho ou produto.

\subsection{Variáveis Antropométricas para o Dimensionamento de Tesouras de Corte e Costura}

As recomendações para o dimensionamento de tesouras de corte e costura que aqui apresentamos estão baseadas no referencial teórico levantado, assim como nas referências de Difrient (1981) cujas indicações mostraram que o correto dimensionamento de um produto fundamentais para o conforto dos usuários e a prevenção de patologias.

Ressaltamos que as recomendações aqui elaboradas apenas servem como referência para um primeiro passo ao se dimensionar uma tesoura de corte e costura. Estes dados são teóricos e devem ser exaustivamente testados quanto à validade através da elaboração de testes antes da elaboração do produto final quando feito sob medida para um único usuário ou encaminhamento dos projetos para linha de produção.

Foram levantadas as variáveis antropométricas para dimensionamento considerando os 2,50 e 97,5 o percentis, sendo o 2,50 da mulher e 9,7,5 do homem de forma a atender a $95 \%$ da população usuária. 
Quadro 1 - Variáveis Antropométricas para dimensionamento de Tesoura de Corte e Costura

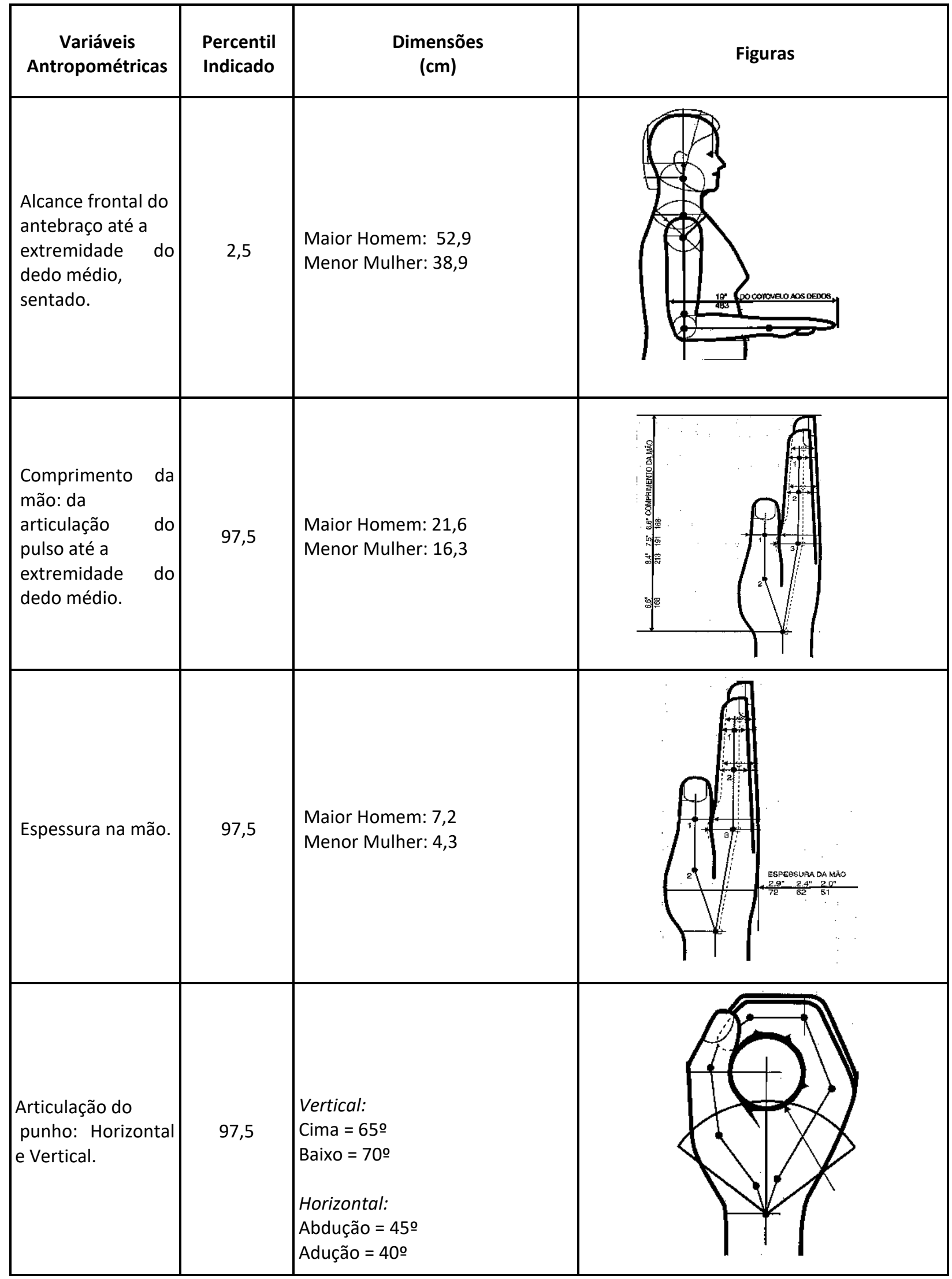




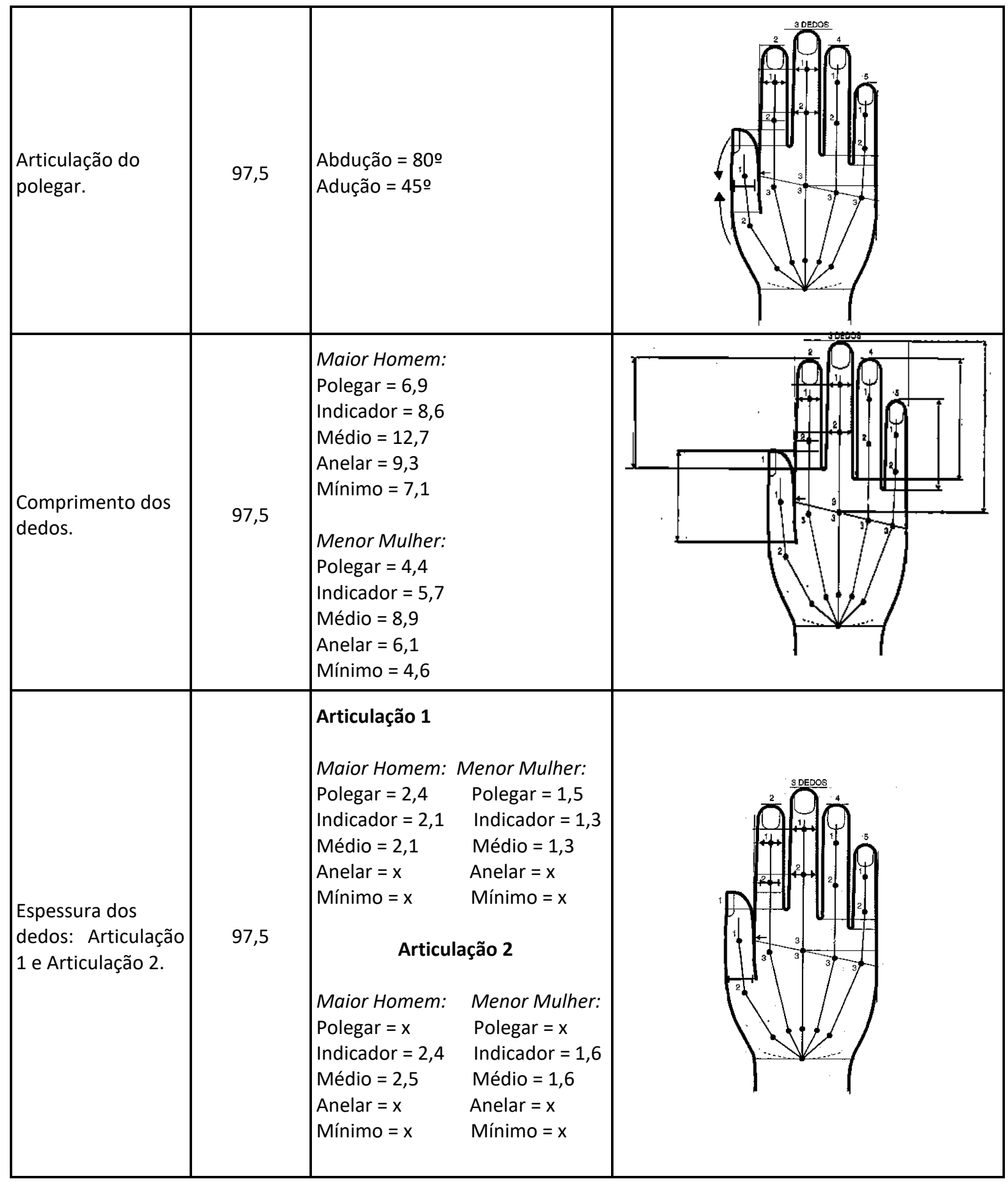




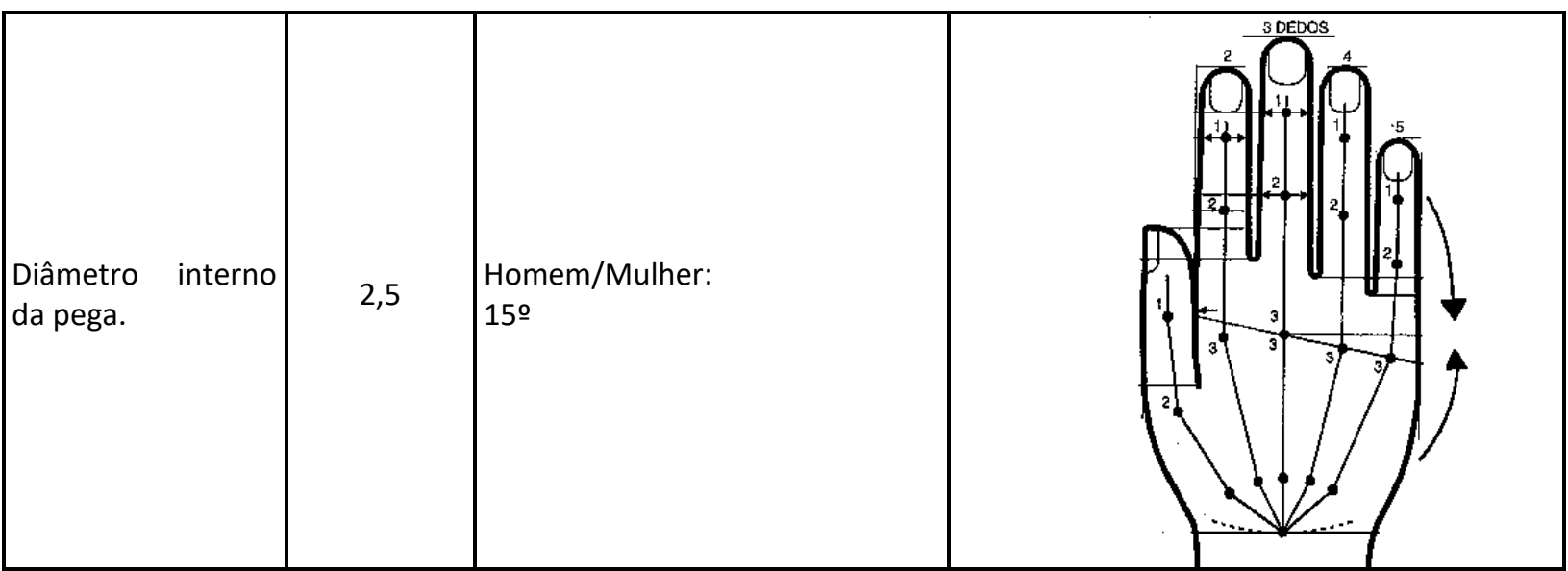

Fonte: Elaborado pelos autores com base na pesquisa realizada. Imagens de Difrient (1981).

\section{Considerações Finais}

Para que as tesouras utilizadas por profissionais de corte e costura e possam atender de forma ergonômica aos usuários, elas devem sofrer ajustes que atendam aos diferentes percentis, minimizando acidentes e doenças ocupacionais, bem como otimizando a produtividade, o conforto, a satisfação e o bem-estar do usuário. Lewis \& Narayan (1993, apud Seixas, Silveira e Pequini, 2001) considera que simples, mas significativas alterações no desenho de equipamentos manuais podem diminuir a potencialidade de doenças relacionadas às atividades deste gênero. Sendo assim, as tesouras de corte e costura analisadas, caracterizadas como equipamentos manuais, obedecem a um design de pega e empunhadura que não leva em conta os aspectos ergonômicos e anatômicos, desconsiderando a usabilidade do produto, bem como a variação antropométrica de seus usuários. Desta forma, recomenda-se para a configuração morfológica do produto, os seguintes itens tendo como referência os requisitos para escova de cabelo para profissionais:

- Evitar cantos agudos e ressaltos;

- Preservar a pele e toda a estrutura da mão humana;

- Ser aderente;

- Apresentar empunhadura tão extensa quanto possível, permitindo a maior força com menor esforço e o uso por parte de usuários de percentis extremos (2,5ㅇ e 95우);

- Possuir peso equilibrado;

- No contexto da usabilidade das tesouras de corte e costura e a atividade na qual está inserida, recomenda-se ainda: minimizar o desenvolvimento de tensões musculares; e apresentar-se apta ao uso em diferentes posições e diferentes mãos - direita ou esquerda;

Vale ressaltar que a população de usuários das tesouras de corte e costura é extensa e muito heterogênea. Com isto, deve-se levar em consideração, para a destas, a variação significativa entre dimensões de mãos masculinas e mãos femininas de forma a compatibilizar as áreas acionais de usuários extremos; bem como os aspectos biomecânicos em que força de preensão da mão masculina é quase o dobro da mão feminina. Deve-se considerar, também, a extensa faixa etária dos usuários, segunda a qual, a força de preensão será menor quanto maior for a idade. (SEIXAS, SILVEIRA e PEQUINI, 2001), 
No design da empunhadura, deve-se considerar a textura não apenas como elemento estético, mas também funcional. A ausência de textura induz a uma maior força de preensão da mão, a incidência de pressões indevidas. A textura permite o aumento da fricção entre a mão e a tesoura.

Com a utilização dos requisitos e das recomendações descritas, acredita-se em uma significativa redução de doenças ocupacionais e acidentes de trabalho, além da garantia do conforto do usuário. No entanto, concluímos que os dados apresentados não são suficientes para um diagnóstico preciso, havendo a necessidade de um aprofundamento da pesquisa de forma mais criteriosa e quantitativa, utilizando aparelhos de medição dos esforços musculares exigidos para o perfeito desempenho da tarefa; o registro das posturas assumidas pelos profissionais através de fotos e radiografias; além de uma análise enfática dos agentes externos que influenciam diretamente na realização da tarefa e, indiretamente, provocam custos humanos.

\section{Referências}

BOUERI, José Jorge. Antropometria aplicada à Arquitetura, Urbanismo e Desenho Industrial. São Paulo, FAU/USP, 1991, v. 1.

DEIMLING, Moacir Francisco; PESAMOSCA, Daniela. ANALISE ERGONÔMICA DO TRABALHO (AET) EM UMA EMPRESA DE CONFECÇÕES. Iberoamerican Journal of Industrial Engineering, Florianópolis,, v. 6, n. 11, p.37-58, 01 jan. 2014. Anual.

DEVIDES Maria T.C. Design, Projeto e Produto: $O$ desenvolvimento de móveis nas indústrias do Pólo Moveleiro de Arapongas, PR. Bauru, SP, 2006.

DIFFRIENT, Niels; TILLEY, Alvin; HARMAN, David. Humanscale. Massachusetts: Henry Dreyfuss Associates, 1981 v. 1 ao 9.

DUL, J. \& WEERDMEESTER, B. Ergonomia Prática. São Paulo: Edgard Blücher, 1995.

ESTIVALET, Patrícia Steinner et al. Avaliação ergonômica de máquina de costura. XXIV Encontro Nac. de Eng. de Produção, Florianópolis, v. 1, n. 1, p. 1-7, 05 nov. 2004, Anual.

FONTOURA, Antônio M. e Cláudia R. Hasegawa, ZACAR. Quando o design mexe com a gente. In: abc Design. Ed n. 25. Curitiba, 2008. ISSN 1676-5656.

GUIMARÃES, Lia Buarque Macedo de. Ergonomia do produto: Antropometria, Fisiologia, Biomecânica. Porto Alegre: Feeng, 2004. 1 v. (2).

IIDA, Itiro; BUARQUE, Lia. Ergonomia: projeto e produção. São Paulo: Blücher, 2016.

LÖBACH, Bernd. Design Industrial: bases para a configuração dos produtos industriais. São Paulo: Edgar Blücher, 2001

JARUFE, Manuel Salomon Salazar; MEDEIROS, Rodrigo Loureiro. ANÁLISE ERGONÔMICA E CONCEPÇÃO DE POSTO DE TRABALHO DE COSTUREIRA. Xxix Encontro Nacional de Engenharia de ProduÇÃo, Salvador, v. 1, n. 1, p.1-9, 09 out. 2009. Anual.

JOFFILY, Ruth. QUANDO FOI CRIADA A PROFISSÃO DE COSTUREIRA? Vista-se Como VocÊ É!, São Paulo, p.1-3, 01 maio 2014.2 Disponível <http://vistasecomovocee.blogspot.com.br/2014/05/quando-foi-criada-profissao-de.html>. Acesso em: 13 set. 2016.em: 13 set. 2016. 
KROEMER, K. H. E.; GRADJEAN, E. Manual de ergonomia: Adaptando o trabalho ao homem. 5. ed. Porto Alegrae: Bookman, 2005. 327 p. Tradução Lia Buarque Guimarãaes.

LEAL, Marcus Costa Lima Verde et al. Análise ergonômica do posto de trabalho de costureiras de uma confecção. Depto. De Engenharia Mecânica e Produção, Fortaleza, v. 1, n. 1, p. 1-2, 13 set. 2016. Anual.

MAGAZINE LUIZA (Brasil). A origem e evolução da costura. Lu Explica, São Paulo, v. 1, n. 1, p.0-0, 13 set. 2016. Mensal. Disponível em: <http://www.magazineluiza.com.br/portaldalu/a-origem-eevolucao-da-costura/2806/>. Acesso em: 13 set. 2016.

MARIÑOPEQUINI, Suzi. A evolução tecnológica da bicicleta e suas implicações ergonômicas para a máquina humana: problemas na coluna vertebral $x$ bicicletas dos tipos Speed e Mountain bike. 2000. 200 f. Dissertação (Mestrado) - Curso de Arquitetura e Urbanismo, Arquitetura, Universidade de São Paulo, São Paulo, 2000.

MARIÑOPEQUINI, SUzi. Ergonomia aplicada ao design de produtos: Um estudo de caso sobre o design de bicicletas. 2005. 630 f. Tese (Doutorado) - Curso de Arquitetura e Urbanismo, Arquitetura, Universidade de São Paulo, São Paulo, 2005.

MORAIS, Anamaria de (A). Aplicação de dados antropométricos dimensionamento da interface homem-maquina. Dissertação de mestrado. Rio de Janeiro: COPPE/UFRJ,1983.

MORAES, Anamaria de (B). Conformação da interface homem-máquina: usuários extremos versus homem brasileiro. In: MORAES, A.; VELLOSO, F. (org) Anais do 20 Encontro carioca de ergonomia. Rio de Janeiro: ABERGO, 1994, p. 33 - 45.

PANERO, Juliua MARTIN, Zelnik. Dimensionamento Humano para Espaços Interiores: Um Livro De Consulta e Referência Para Projetos. Editora: GGbrasil. Ano: 2003.

PORTARIA GR 6713/2015 (Brasil).Plano de classificação de funções. São Paulo: São Paulo, 2015. 2p.

PRAIA, Darllene Tinoco et al. Risco ergonômico em costureiras da indústria de confecções de Coari - AM. Revista Pesquisa em Fisioterapia, Manaus, p.107-117, 03 dez. 2013.

PRIME. Mercado de trabalho de corte e costura exige um bom preparo. Prime cursos. São Paulo, v. 1, n 1, p.1-2, 10 ago. 2014. Semanal.

QUARESMA, Maria Manuela Rupp. Aplicação de dados antropométricos em projeto de design: como projetar corretamente produtos ergonômicos. Dissertação (Mestrado em Design). PUC/Rio, Rio de Janeiro, 2001.

RENAULT, Luiz Otavio Linhares (Org.). COSTUREIRA - DOENÇAS OSTEOMUSCULARES TENDÍNEAS DANO MATERIAL E DANO MORAL. Recurso Ordinario Trabalhista, Rio de Janeiro, v. 1, n. 1, p.1-4, 05 set. 2914. Diária.

SEIXAS, Andrea; SILVEIRA, Carina; PEQUINI, Suzi Mariño. ESTUDO ERGONÔMICO DAS ESCOVAS DE CABELO UTILIZADAS POR PROFISSIONAIS DE SALÕES DE BELEZA. 10 Ergodesing, Rio de Janeiro, v. 1, n. 1, p.1-5, 01 maio 2001. Anual.

SENA, Rafaela Barbosa de et al. Análise dos riscos ergonômicos em costureiras utilizando o software ERA (Ergonomic Risk Analisys) em uma empresa do Polo de confecções do agreste Pernambuco. XXVIII Encontro Nacional de Engenharia de Produção, Rio de Janeiro, v. 1, n. 1, p 1-1, 16 out. 2008, Anual. 
SOARES, J. F.; SIQUEIRA, A. L. Introdução à estatística médica. Belo Horizonte: Departamento de Estatística - UFMG, 1999.

SOUZA, Norma Suely Souto; SANTANA, Vilma Sousa. Incidência cumulativa anual de doenças musculoesqueléticas incapacitantes relacionadas ao trabalho em uma área urbana do Brasil. Caderno Saúde Pública, Rio de Janeiro, v. 11, n. 27, p.2124-2134, 01 nov. 2011. Semestral.

Triviños, A. N. S. Introdução à pesquisa em ciências sociais: A pesquisa qualitativa em educação. São Paulo, Atlas, 1987.

VIANA, Ilca Oliveira. Metodologia de Trabalho Científico: Um enfoque didático da produção científica. São Paulo: Epu, 2001. 304 p. 